\title{
Rho Family GTPases Regulate Mammary Epithelium Cell Growth and Metastasis Through Distinguishable Pathways
}

\author{
Boumediene Bouzahzah, ${ }^{1}$ Chris Albanese, ${ }^{1}$ Fayyaz Ahmed, ${ }^{1}$ Fiona Pixley, ${ }^{1}$ Michael P. Lisanti, ${ }^{2}$ \\ Jeffrey D. Segall, ${ }^{3}$ John Condeelis, ${ }^{3}$ David Joyce, ${ }^{4}$ Audrey Minden, ${ }^{5}$ Channing J. Der, ${ }^{6}$ Amanda Chan, ${ }^{7}$ \\ Marc Symons, ${ }^{7}$ and Richard G. Pestell ${ }^{1}$ \\ ${ }^{1}$ The Albert Einstein Cancer Center, Departments of Medicine and Developmental and Molecular Biology \\ ${ }^{2}$ Department of Molecular Pharmacology \\ ${ }^{3}$ Department of Anatomy and Structural Biology, Albert Einstein College of Medicine, Bronx, NY, USA \\ ${ }^{4}$ Department of Pharmacology, The University of Western Australia, Nedlands, WA, AU \\ ${ }^{5}$ Columbia University, Biological Sciences, Sherman Fairchild Center, NY, NY, USA \\ ${ }^{6}$ Department of Pharmacology and Lineberger Comprehensive Cancer Center, University of North Carolina \\ School of Medicine, Chapel Hill, NC, USA \\ ${ }^{7}$ Laboratory of Molecular Oncology, Picower Institute for Medical Research, Manhasset, New York, USA \\ Contributed by M. Symons. Accepted October 31, 2001
}

\begin{abstract}
Background: Relatively few genes have been shown to directly affect the metastatic phenotype of breast cancer epithelial cells in vivo. The Rho family of proteins, including the Rho, Rac and Cdc42 subfamilies, are related to the small GTP binding protein Ras and regulate diverse biological processes including gene transcription, cytoskeletal organization, cell proliferation and transformation. The effects of Cdc42, Rac and Rho on the actin cytoskeleton suggested a possible role for Rho proteins in cellular motility and metastasis, however a formal analysis of the role of Rho proteins in breast cancer cellular growth and metastasis in vivo had not previously been performed.

Materials and Methods: We generated a panel of MTLn3 rat mammary adenocarcinoma cells that expressed similar levels of dominant inhibitory mutants of Cdc42-, Rac- and Rho-dependent signaling, to examine the contribution of these GTPases to cell spreading, guided chemotaxis, and metastasis in vivo. The ability of Rho proteins to regulate intravasation into the peripheral blood was determined by implanting MTLn3 cell stable dominant negative lines in nude mice and measuring the formation of breast cancer
\end{abstract}

cell colonies grown from the peripheral blood. Serial sectioning of the lungs was performed to determine the presence of metastasis in mice in which mammary tumors expressing the dominant negative Rho family proteins had grown to a similar size.

Results: Cell spreading of MTLn3 cells was selectively abrogated by N17Racl. N19RhoA and N17Cdc42 reduced the number of focal contacts (FCs) and disrupted the colocalization of vinculin with phosphotyrosine at FCs. While N17Racl and N17Cdc42 preferentially inhibited colony formation in soft agar, all three GTPases affected cell growth in vivo. To distinguish effects on tumorigenicity from intravasation into the bloodstream, implanted tumors were grown to the same size in nude mice. Each dominant inhibitory Rho protein reduced intravasation into the peripheral blood. Lung metastasis of MTLn3 cells was also abrogated by the dominant inhibitory Rho proteins, despite the presence of residual CFU.

Conclusions: These studies demonstrate for the first time a critical role for the Rho GTPases involving independent signaling pathways to limit mammary tumor cellular growth and metastasis in vivo.

\section{Introduction}

Rho family proteins are closely related to the small GTP binding protein Ras (1). Rho GTPases cycle between an active GTP-bound state and an inactive GDP-bound state to transduce diverse signals from cell surface receptors to intracellular targets (1). Rho proteins regulate a diverse spectrum of biological

Send correspondence and reprint requests to: Richard G. Pestell, The Albert Einstein Cancer Center, Department of Medicine, Albert Einstein College of Medicine, Chanin 302, 1300 Morris Park Ave, Bronx, New York, 10461, USA. Phone: 718-430-8662; fax: 718-430-8674; e-mail: pestell@aecom.yu.edu. processes including regulation of gene transcription, superoxide production, changes in cytoskeletal organization, cell proliferation and transformation (1-4). Analyses performed predominantly in fibroblasts, employing microinjection of dominant-active or dominant-negative mutants, demonstrated that specific Rho proteins regulate distinct functions (1). The functional specificity of Rho GTPases is transduced, at least in part, by an interaction with specific effector proteins that coordinate the activation of multiple signaling cascades (1). The regulation of the actin cytoskeleton and specialised cellular adhesion structures is also quite selective for distinct members of the Rho 
family. Thus, activated RhoA stimulates stress fiber formation (5), Racl controls growth factor-induced lamellipod formation in Swiss 3T3 fibroblasts (2) and Cdc42 regulates filopodial protrusion $(6,7)$

The effects of Cdc42, Rac and Rho on the actin cytoskeleton and cellular adhesion suggested a possible role for Rho proteins in cellular motility. A role for Rho proteins in migration of fibroblasts and neutrophils was demonstrated using the $\mathrm{C} 3$ exoenzyme and Rho-GDI (GDP dissociation inhibitor) to block Rho function $(8,9)$. In Bacl.2F5 macrophages, inhibition of Rac and Rho function blocked cell migration in response to CSF-1, while a dominant inhibitory Cdc42 enhanced cell migration (10). Rac activity is also required for PDGF-BB-induced migration of Ratl cells across a porous membrane (11). In T47D mammary epithelial cells, activated Racl and Cdc42, but not RhoA, enhanced cell migration across filters coated with collagen (12), Cellular migration through increasingly complex surfaces such as a three dimensional (3D) collagen gel requires distinct properties of Rho proteins (13). Invasion of 3D collagen matrices by Ratl cells was inhibited by dominant negative mutants of Cdc42 and Racl indicating fibroblast invasion requires optimal level of activity of multiple Rho family members (13). The process of cellular metastasis in vivo is a still more complex process involving several distinct phases including invasion through tissue structures, intravasation and survival in the peripheral blood and the ability to adhere at a distant site. It is predicted that Rho GTPases might regulate mammary epithelial cell invasion and metastasis in vivo. The contribution of the Rho proteins to in vivo mammary tumor bioassays such as tumor blood burden and lung metastasis is therefore of fundamental importance $(14,15)$. As the role of Rac, Rho and Cdc42 to the components governing metastasis in vivo had not previously been formally assessed, we employed a syngeneic model to address this question.

In this study we employed MTLn3 cells that were originally derived from a lung metastasis of the 13762 rat mammary adenocarcinoma $(16,17)$. The effects of Epithelial Growth Factor (EGF) on guided chemotaxis have been extensively studied in the MTLn3 cells. EGF, through binding to its receptor, functions as a chemoattractant for a number of different cell types and is thought to enhance the migration and invasion of tumor cells (18-21). EGF-mediated chemotaxis of MTLn3 cells was shown to include actin polymerization at the leading edge of the lamellipod to enable cellular extension and motility (22-24). In this study, we used MTLn3 cells stably expressing Rho inhibitory proteins to examine the role of the Rho family GTPases in coordinating cytoskeletal reorganization and in the regulation of metastasis. We demonstrate for the first time separable signaling pathways regulated by Rho GTPases that together contribute to in vivo mammary epithelial tumor metastasis.

\section{Materials and Methods \\ Cell Culture, Proliferation and Transformation Assays}

Cell culture was performed as previously described (24). Cells were grown in $\alpha$-MEM (Gibco), supplemented with $5 \%$ fetal calf serum and antibiotics. For all experiments, unless otherwise mentioned, MTLn3 cells were plated in regular medium for $24 \mathrm{~h}$ at low density on tissue culture dishes (Falcon), or MaTek dishes (MaTek Corporation, Ashland, MA), which had been previously coated for $2 \mathrm{~h}$ at room temperature with rat tail collagen type 1 (Collaborative Biomedical, Bedford, MA) at $30 \mu \mathrm{g} / \mathrm{ml}$ in DPBS (Gibco). MTLn3 cells were starved for $3 \mathrm{~h}$ prior to the experiment in $\alpha$-MEM medium supplemented with $0.35 \%$ bovine serum albumin (BSA) and $12 \mathrm{mM}$ HEPES (starvation medium). Stimulation was done with a final concentration of $5 \mathrm{nM}$ murine EGF (Life Technologies) in starvation medium.

The plasmids pEXV, Myc-N17Racl, MycN19RhoA (25), pCMV5, and Flag-N17Cdc42 (26) have been previously described. MTLn3 cells were stably transfected with the epitope-tagged Rho family GTPase dominant negative mutants and pCNeo, selected using G418 $(800 \mathrm{ng} / \mathrm{ml})$ and maintained in G418 $(400 \mathrm{ng} / \mathrm{ml})$. Expression of the mutant Rho proteins was confirmed by western blot of the epitope tag. For cellular proliferation assays, the MTLn3 cells encoding Rho family inhibitory proteins, or the parental line containing the empty vector control, (pEXV, pCMV), were plated in 6-well tissue culture plates. After six days growth in regular culture medium $(\alpha$-MEM, $5 \%$ FBS) cells were trypsinized, harvested and counted using a hemocytometer. The soft agar growth assays was performed as previously described (27-29). MTLn3 stable cells $\left(3 \times 10^{4}\right.$ cells) were suspended in $3 \mathrm{ml}$ of $\alpha$-MEM containing $5 \%$ FBS and $0.33 \%$ SeaPlaque low-melting-temperature agarose (FMC Bioproducts). The suspension was plated on $60 \mathrm{~mm}$ dishes containing a $2 \mathrm{ml}$ layer of solidified $\alpha$-MEM, $5 \%$ FBS and $0.5 \%$ SeaPlaque agarose, in quadruplicate. The cells were allowed to settle at the interface between these layers for $30 \mathrm{~min}$ at $37^{\circ} \mathrm{C}$. Cells were fed every 3 days by overlaying with $2 \mathrm{ml}$ of complete medium containing $0.33 \%$ SeaPlaque agarose. After 15 days, the plates were examined and the colonies were counted under a Nikon Phase contrast microscope at $4 \times$ or $6 \times$ magnification. Experimental values represent the average number of foci in the $60 \mathrm{~mm}$ plates for each experimental condition; error bars represent the observed SEM between the 4 plates.

\section{Immunofluorescence and Rhodamine-Phalloidin Staining of Filamentous Actin (F-actin)}

Cells were seeded onto $22 \mathrm{~mm}$ square glass cover slips (Becton Dickinson, Bedford, MA) coated with rat tail collagen type $1(27 \mu \mathrm{g} / \mathrm{ml})$ in 6-well tissue culture plates. When $70-80 \%$ confluent, cells were 
rinsed with $1 \times$ PBS at $37^{\circ} \mathrm{C}$, fixed in $3.7 \%$ formaldehyde in buffer $\mathrm{F}(5 \mathrm{mM} \mathrm{KCl}, 137 \mathrm{mM} \mathrm{NaCl}, 4 \mathrm{mM}$ $\mathrm{NaHCO}_{3}, 0.4 \mathrm{mM} \quad \mathrm{KH}_{2} \mathrm{PO}_{4}, \quad 1.1 \mathrm{mM} \quad \mathrm{Na}_{2} \mathrm{HPO}_{4}$, $2 \mathrm{mM} \mathrm{MgCl} 2,5 \mathrm{mM}$ PIPES, pH 7.2, 2 mM EGTA, 5.5 $\mathrm{mM}$ glucose) for $5 \mathrm{~min}$ at $37^{\circ} \mathrm{C}$, extracted in $0.5 \%$ Triton X-100 in buffer $\mathrm{F}$ for 20 min at room temperature and washed in $0.1 \mathrm{M}$ glycine in buffer $\mathrm{F}$ for 10 min at room temperature. The cover slips were washed 5 times for 5 min in $1 \times$ TBS, wicked dry and placed on Parafilm in a humidified chamber and $150 \mathrm{ml}$ of $1 \%$ BSA, $10 \%$ goat serum in $1 \times$ TBS with rhodamine-phalloidin $(0.5 \mathrm{mM})$ (Molecular Probes, Eugene, OR) added for 20-30 min. Excess rhodaminephalloidin was washed from the cover slips, 5 times for 5 min with $1 \%$ BSA in $1 \times$ TBS and, if no immunofluorescent staining was carried out, the cover slips were mounted in Prolong reagent (Molecular Probes, Eugene, OR). For immunofluorescent staining, the cells were incubated at room temperature for $60 \mathrm{~min}$ with primary antibody after blocking. The cover slips were then washed 3 times for $10 \mathrm{~min}$ in $1 \%$ BSA in $1 \times$ TBS and incubated with secondary antibody for $45-60 \mathrm{~min}$ at room temperature before a final series of three 10 min washes in $1 \%$ BSA in $1 \times$ TBS. If two primary antibodies were used, the antibodies were added sequentially and each directly followed by incubation with their respective secondary antibodies. The cover slips were mounted as before and examined under an olympus $1 \times 70$ inverted microscope with images recorded using a Photometrics $\mathrm{CH}$ l cooled CCD camera.

Antibodies used included an anti-phosphotyrosine (P112300 polyclonal antibody, Transduction Labs), anti-vinculin (V4505, Sigma), anti-Flag antibody (Sigma, (M2)), and anti-Myc (9E10, Santa Cruz, mouse monoclonal).

\section{Microchemotaxis Assay}

Chemotactic responses were assessed using the 48well chemotaxis chamber (Neuroprobe, Cabin, MD, USA) following the manufacturers instructions. A Nucleopore filter with $8 \mu \mathrm{m}$ pores (Osmonics/Poretics Products, Livermore, CA, USA) was coated with rat tail collagen type 1 at a final concentration of $35.6 \mu \mathrm{g} / \mathrm{ml}$ in DPBS without calcium or magnesium (JRH Biosciences) for 2 hours. MTLn3 cells were cultured in MEM medium with 5\% FBS and 0.5\% Penicillin/Streptomycin on $10 \mathrm{~cm}$ plates. Medium was aspirated and replaced with growth medium containing $12 \mathrm{mM}$ HEPES pH 7.4 and BSA $0.35 \%$ in MEM (termed MEMH) without serum or antibiotics for 2 hours. Cells were then harvested with $26.6 \mathrm{mM}$ EDTA in DPBS, resuspended in MEMH and counted. The lower wells of the chamber were filled with $30 \mu \mathrm{l}$ MEMH containing appropriate concentration of EGF (Life Technologies) or buffer, then the chamber was assembled incorporating the collagen-coated filter. The stock of EGF was prepared in filtered DPBS. The upper wells were then filled with MEMH containing 20,000 cells/well in a total volume of $50 \mu \mathrm{l}$. The chamber was incubated at $37^{\circ} \mathrm{C}$ for $3 \mathrm{~h}$, disassembled and the upper side of the filter scraped to remove cells that had not traveled through the filter. The filters were fixed in $3.7 \%$ formaldehyde in DPBS for $30 \mathrm{~min}$, washed twice in water and stained for 12-18 $\mathrm{h}$ in hematoxylin. The filters were then rinsed in water and mounted for viewing. Results are means \pm SEM from 5 - to 8 separate experiments.

\section{Lamellipod Extension and Spreading Assays}

Cells were seeded onto $22 \mathrm{~mm}$ square collagencoated glass cover slips in 6-well tissue culture plates and treated or not with $5 \mathrm{nM}$ EGF for $3 \mathrm{~min}$. Cell were fixed in $3.7 \%$ formaldehyde, extracted in $0.5 \%$ Triton X-100 and mounted. The extension of lamellipodia was assessed as previously described by us $(22,28)$. All samples were examined under an Olympus $1 \times 70$ inverted microscope with images recorded using a Photometrics CHI cooled CCD camera. A total of 300 cells were examined.

For the spreading assays, MTLn3 cells were plated $\left(10^{4}\right.$ cells/well $)$ on a collagen coated $(27 \mu \mathrm{g} / \mathrm{ml})$ 6-well plate. At several time points after plating, the cells were viewed using phase contrast and a $10 \times$ objective. The number of spread cells was counted by visual inspection using a $5 \times 5$ grid. Cells that turned phase-dense during the spreading process and displayed at least one protrusion were counted as spread. A total of 300 cells were counted in five different fields that were selected at random. To observe the F-actin in MTLn3 cells, the cells were fixed and stained with FITC-phalloidin after plating for various times. The data were expressed as mean \pm SEM for percentages of positive cells in the five fields.

\section{Western Blots}

Immunoprecipitation western blotting was performed as previously described using either the Flag or Myc antibodies $(30,31)$. The abundance of Fak, Talin, and Vinculin proteins was determined by western analysis as previously described $(32,33)$, using anti-Vinculin antibody (Sigma), anti-focal adhesion kinase (FAK) antibody (F15020 polyconal antibody, Transduction Labs), guanine nucleotide dissociation inhibitor (GDI) antibody (Acknowledgments, 25), and anti-Talin monoclonal antibody (8d4, Sigma). Cell homogenates $(50 \mu \mathrm{g})$ were separated in an SDS-12\% polyacrylamide gel and transferred electrophoretically to a nitrocellulose membrane (Micron Separations Inc., Westborough, MA). After transfer, the gel was stained with Coomassie blue as a control for blotting efficiency. The blotting membrane was incubated for $2 \mathrm{~h}$ at $25^{\circ} \mathrm{C}$ in T-PBS (PBS $+0.05 \%$ Tween 20 ) buffer supplemented with $5 \%$ (wt/vol) dry milk to block non-specific binding sites. Following $6 \mathrm{~h}$ incubation with primary antibody at a 1:5000 dilution (GDI) in T-PBS buffer containing $0.05 \%$ (vol/vol) Tween 20, the membrane was washed with the same buffer. The membrane 
was incubated with goat anti-mouse horseradish peroxidase second antibody (Santa Cruz Biotechnology, Santa Cruz, CA) and washed again. The protein was visualized by the enhanced chemiluminescence system (Kirkegaard and Perry Laboratories, Gaithersburg, MD).

In Vivo Tumor Growth, Blood Burden, and Lung Metastasis Assay

To determine the effect of dominant negative N17Rac, N19Rho and N17Cdc42 on MTLn3 cell metastasis, parental and stably transfected MTLn3 cells were injected into the subcutaneous tissue of 6- to 8-week old nude mice (strain Balb/cAnNCr-nuBR, National Cancer Institute) as previously described $(25,34)$. Experiments were conducted under an approved protocol of the AECOM animal ethics committee. Cells were trypsinized, counted, washed twice and resuspended in ice-cold sterile PBS. Nude mice were anesthetized lightly with Methofane (Schering-Plough Animal Health) and injected with $10^{6}$ viable cells in $0.1 \mathrm{ml}$ of PBS. Tumors were palpated every 3- to 4 days after the first week and measured with calipers (mean tumor diameter) to quantitate tumor size. Animals were euthanized 5- to 8.5 weeks after cells were injected. Tumors growing at the site of injection were measured and then removed and rinsed in ice-cold PBS. Samples of tumor tissue were rapidly frozen in liquid nitrogen for further analysis.

Tumor cell blood burden was determined as previously described (35) by placing nude mice with a 5 week old tumor under methofane anesthesia and removing $1 \mathrm{ml}$ of blood via heart puncture. The blood was then spun at 5,000 rpm and the serum layer and buffy coat region were plated into $\alpha$-MEM growth medium. The following day, plates were rinsed $2 \times$ with Dulbeco's PBS (Gibco) to remove red blood cells and regular growth medium (as above) was added. After six days, all clones in the dish were counted. For experiments in which the Rho family dominant inhibitory MTLn3 cells were grown to the same size as vector controls, the subcutaneous tumors were grown for 8.5 weeks.

For measurement of metastasis, excised lungs were placed in $3.7 \%$ formaldehyde, mounted in paraffin, sectioned and stained with H\&E. Serial slices of $5 \mu \mathrm{M}$ thickness were methodically viewed throughout the entire lung with sections viewed using a $20 \times$ objective and all visible metastases in a section containing more than 5 cells were counted in each section.

\section{Results}

Effects of Rho Proteins on EGF-induced Stress

Fiber Formation

To investigate the role of Rho family GTPases in MTLn3 metastatic behavior in vivo, we established stably transfected lines. The expression of the various Rho GTPases was confirmed by western blotting of the epitope tagged construct (Fig. 1). Cells extracts
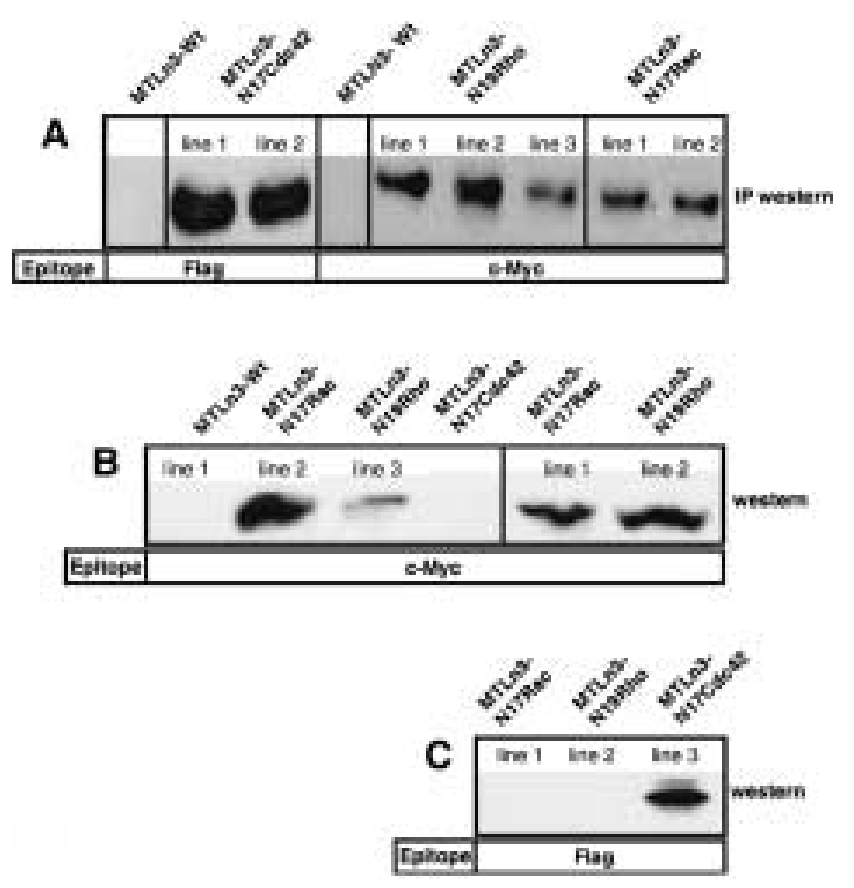

Fig. 1. Expression of dominant inhibitory Rho-family mutants. (A) MTLn3 cells were stably transfected with N17Racl, N19RhoA, N17Cdc42, pEXV (control vector for Rac and Rho) and pCMV5 (control vector for Cdc42). Cell extracts from each cell line were immunoprecipitated with Flag (pCMV5 and N17Cdc42) or Myc (pEXV, N17Racl and N19RhoA) antibodies, separated by SDS-PAGE and identified by western analysis with anti-Flag antibody or anti-Myc antibody. (B,C) MTLn3 cell extracts were separated by SDS-PAGE and western blotting was performed with an antibody to the Flag or Myc epitope.

were either subjected to immunoprecipitation with an antibody to the epitope (Myc or Flag) with subsequent western blotting (Fig. 1A), or subjected to direct western blotting (Fig. 1B,C).

\section{Tyrosine Phosphorylation of Focal Contacts Involves} Rho and Cdc42

Many cultured cells form specialized structures known as focal adhesions to link them to the underlying extracellular matrix (ECM). To assess the focal adhesions, MTLn3 cells were plated on the ECM protein, collagen. Focal contacts (FCs) contain a number of cytoskeletal and submembranal anchor proteins including vinculin, paxillin and talin (36-38), which link the transmembrane integrin receptors to the actin cytoskeleton. FCs are also enriched in signal transduction molecules including focal adhesion kinase (FAK) (39). A characteristic of FCs in fibroblasts is their high level of tyrosine phosphorylation (36). The assembly and tyrosine phosphorylation (pTyr) of proteins in FCs is regulated by cytoplasmic factors including Rho, caldesmon as well as by microtubular integrity $(37,40-45)$. We assessed the distribution of pTyr in the FCs of MTLn3 cells (Fig. 2). FCs were identified by their high abundance of vinculin by double immunofluorescence staining 
with antibodies to pTyr and to vinculin. Cells grown to $70-80 \%$ confluence on collagen-coated glass cover slips were treated with $5 \mathrm{nM}$ EGF or vehicle for either 2 or $4 \mathrm{~h}$ with similar results. In the parental vector control MTLn3 cells, pTyr co-localized with vinculin in the basal state with a modest reduction upon EGF treatment (Fig. 2A), consistent with findings in NR6 fibroblasts (46). A modest reduction in vinculin staining FCs was observed upon EGF treatment at 2 hours. The N17Racl lines displayed abundant pTyr and vinculin, which co-localized upon image merging (Fig. 2C). In contrast, vinculin staining FCs were reduced and co-localization with PTyr disrupted in the N19RhoA (Fig. 2D) and N17Cdc42 lines (Fig. 2B). Western analysis showed comparable total cellular vinculin abundance in the parental and Rho-protein
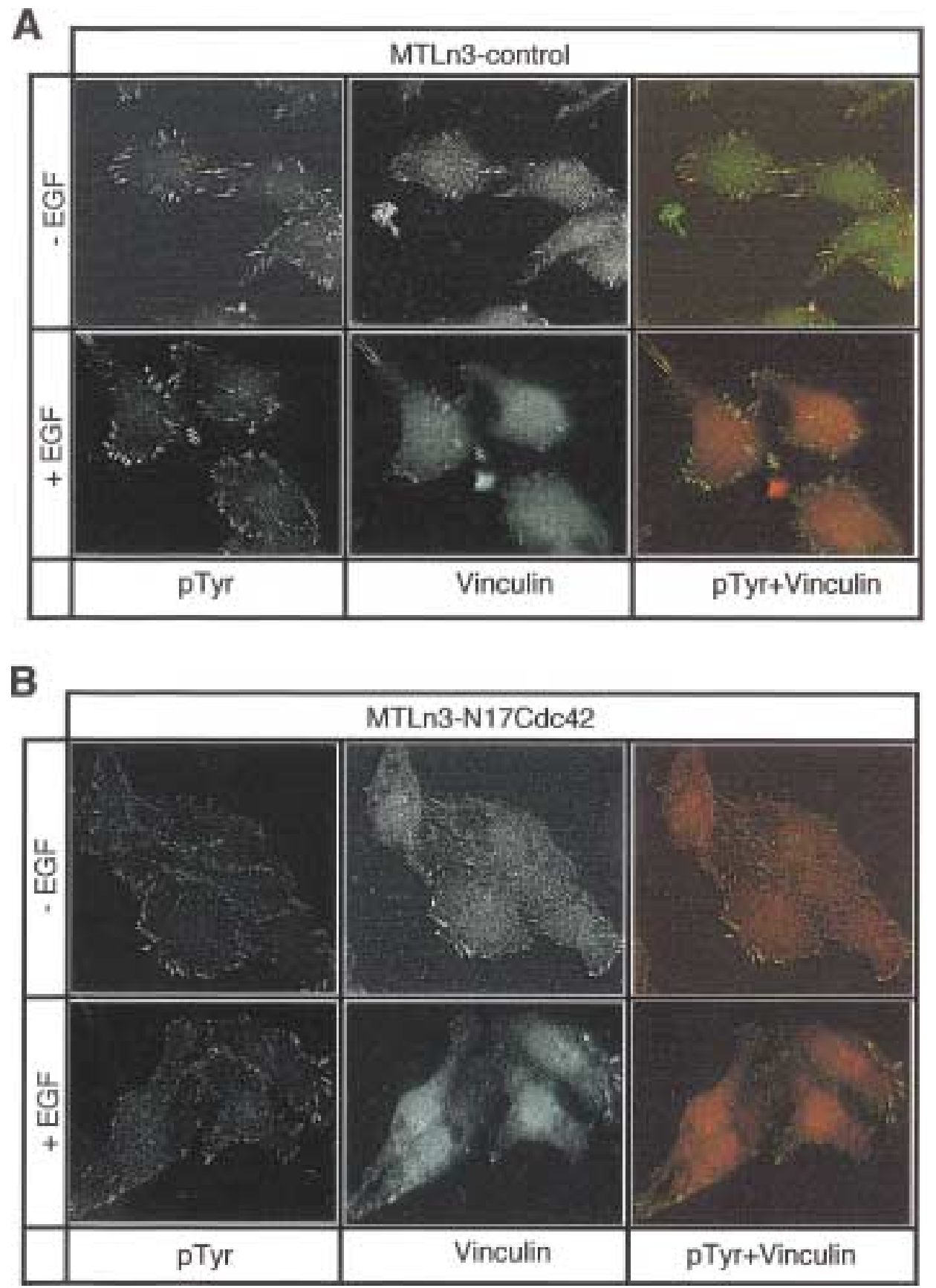

Fig. 2. Phosphotyrosine immunofluorescence at focal adhesions of MTLn3 Rho family mutant stable lines. Cells were seeded onto $22 \mathrm{~mm}$ square collagen-coated glass cover slips and treated with EGF $(5 \mathrm{nM})$ for $4 \mathrm{~h}$. Immunostaining for pTyr and Vinculin were recorded using a cooled CCD camera and the images merged (PY + Vinc). Results are shown for MTLn3-control (A), MTLn3-N17Cdc42 (B), MTLn3-N17Racl (C), and MTLn3-N19RhoA (D). Inhibition of pTyr IF is found in (B), and (D). 

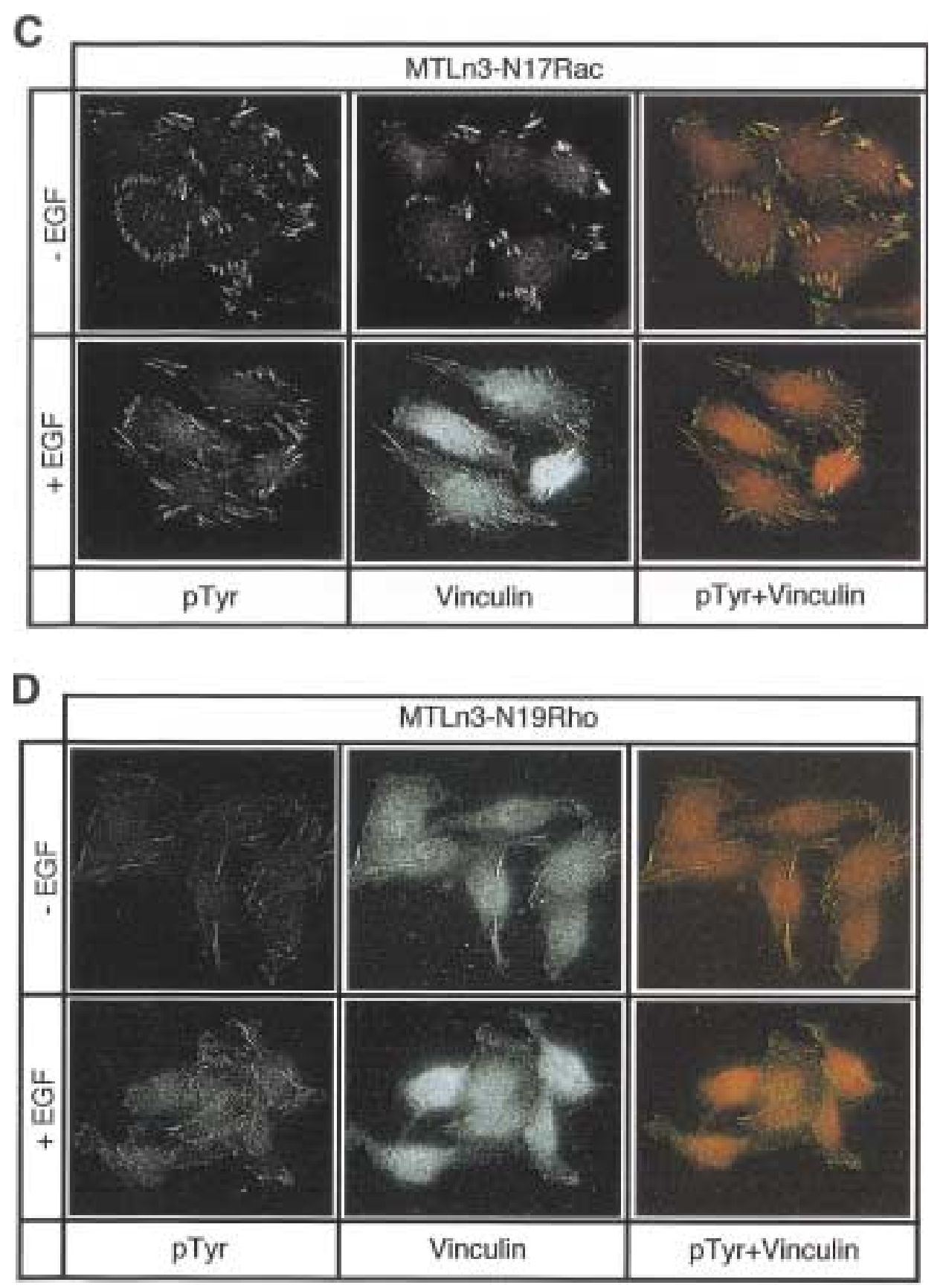

Fig. 2. (Continued)

expressing cell lines (data not shown). These studies suggest that both Rho and Cdc42 activity contribute to the assembly and formation of tyrosine phosphorylated FCs in mammary adenocarcinoma cells and are consistent with the observations that tyrosine phosphorylation and assembly of FCs involves RhoA activity (44).

\section{EGF-induced Chemotaxis}

In recent studies using T47D mammary epithelial cells, activating mutants of Cdc42 or Racl promoted the motile phenotype of these cells (12). The chemotactic response of MTLn3 cells to EGF corresponds with enhanced lamellipod formation (22). We therefore examined the role of the Rho GTPases in EGF-induced guided chemotaxis of MTLn3 cells expressing Rho GTPases using microchemotaxis chambers and increasing concentrations of EGF (Fig. 3). The dominant inhibitory RhoA protein reduced EGF-mediated cell migration by $80 \%$, both at 1 or $10 \mathrm{nM}$ EGF. EGF-induced migration of MTLn3 cells was also reduced by $50 \%$ to $60 \%$ by 

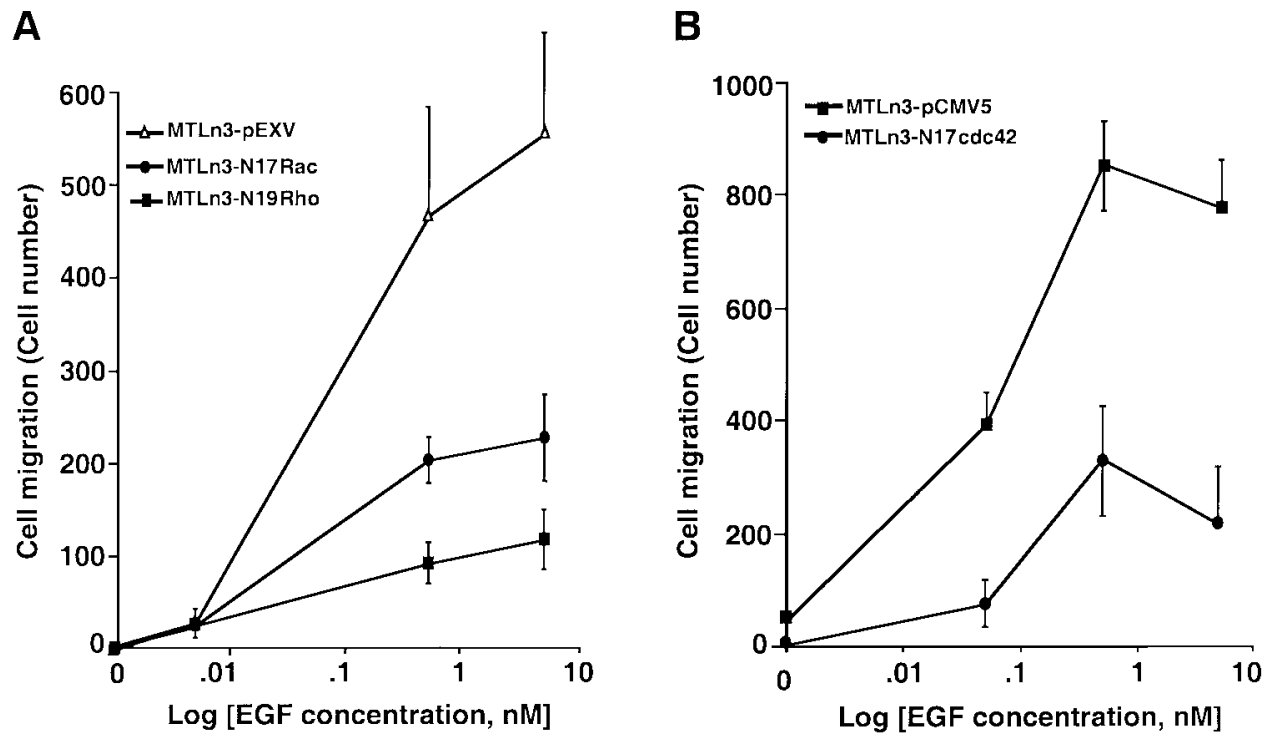

Fig. 3. EGF-induced chemotaxis. Chemotactic responses to EGF were assessed in a 48-well microchemotaxis chamber as described in Materials and Methods. Cell migration was determined for the Rho family dominant inhibitory cell lines, with comparison made to the empty vector control line. The results are mean \pm SEM from 8 and 5 separate experiments, (A and B) respectively.

the dominant inhibitory Racl (Fig. 3A) and Cdc42 (Fig. 3B) proteins compared with empty vector control lines.

\section{Cell Proliferation and Anchorage-independent Growth in MTLn3 Expressing Inhibitory Rho GTPases}

The proliferation of MTLn3 cell lines was measured over 6 days in culture as described in Materials and Methods (Fig. 4). Cell proliferation rates were inhibited by $50 \%$ using the dominant inhibitory N17Cdc42 and N17Racl. In contrast, inhibition of cell proliferation using the N19RhoA mutant was less than $20 \%$, although stress fiber formation was inhibited and tyrosine phosphorylation of focal adhesions was disrupted. These studies suggest that among the Rho family proteins, RhoA regulates the actin cytoskeleton but has modest effects only on cellular proliferation in the MTLn 3 cells.

To extend these studies on cell growth, we analyzed contact-independent growth of these cells in soft agar. Previous studies suggested an important role for Rho family proteins (Rac and Rho) in Ras- and Erb-B2-induced anchorage-independent growth of Ratl cells $(25,47,48)$. Compared with cells stably containing the empty vector ( $\mathrm{pEXV}$ or pCMV5) which formed large colonies in soft agar (Fig. 5B), the colonies of N17Racl-MTLn3 and N17Cdc42-MTLn3 were significantly reduced in both size and number (Fig. 5A,B). In contrast, there was no significant reduction in the number or size of N19RhoA foci in soft agar (Fig. 5A,B). Western blotting confirmed the sustained expression of the Myc epitope-tagged RhoA in NI9RhoA-MTLn3 cells.

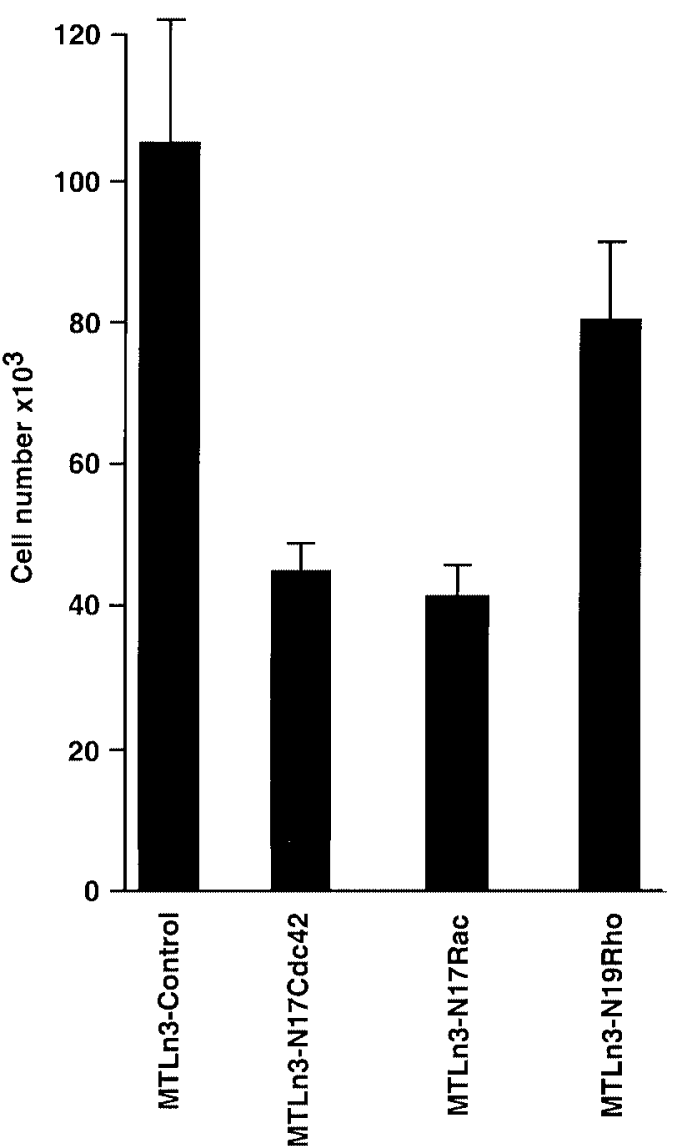

Fig. 4. Cell proliferation rates in MTLn3 inhibitory Rho mutant lines. The MTLn3 cell lines or the lines containing the empty vector controls (pEXV, pCMV5) were plated in 6-well tissue culture plates. After 6 days growth in regular medium ( $\alpha$-MEM, 5\% FBS) cells were trypsinized, harvested and counted using a hemocytometer. The data are shown as mean \pm SEM. 

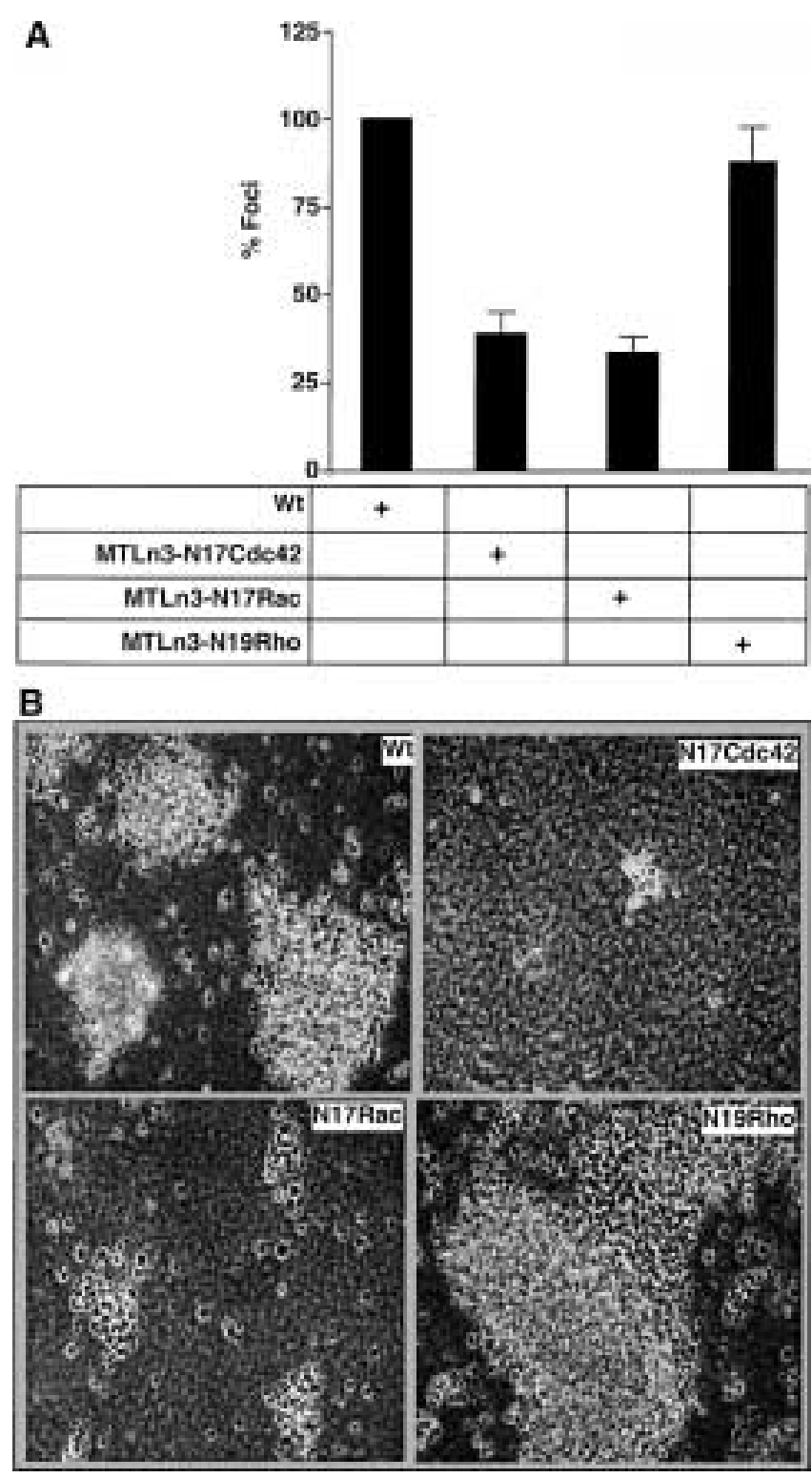

Fig. 5. Dominant inhibitory Rho family proteins reduce contact-independent growth. N17Racl-, N19RhoA- and N17Cdc42-MTLn3 stable cells, or vector control MTLn3 lines, were grown in 6-well plates were assessed for growth on soft agar, as described in Materials and Methods. After 15 days, the plates were examined under a microscope at low magnification $(4 \times$ or $6 \times)$ and the colonies were counted. (A) Experimental values represent the average number of foci in the $60 \mathrm{~mm}$ plates for each experimental condition; error bars represent the observed SEM for the 4 plates done in 3 separate experiments (B) Representative regions of plates.

\section{Cell Spreading Assays}

Previous studies have identified a role for Rho family proteins in Ratl fibroblast spreading on fibronectincoated surfaces (49). To determine the effects of dominant negative N19RhoA, N17Racl and N17Cdc42 expression on actin dynamics in MTLn3 cells, the rate of cell spreading on collagen was assessed at various time points and F-actin staining was assessed simultaneously. F-actin staining was followed using rhodamine phalloidin in serum starved MTLn3 cells. F-actin containing structures were present in serum starved parental MTLn3 lines. Expression of N17Racl inhibited cell spreading of MTLn3 cells on collagen by $90 \%$, compared to vector control cells at $45 \mathrm{~min}$. This inhibition of cell protrusion and spreading by N17Racl was maintained at $140 \mathrm{~min}$ (Fig. 6A) and 310 min (Fig. 6B). MTLn3 cells expressing N19Rho or N17Cdc42 showed similar cell spreading as the parental controls (Fig. 6C). Similar trends were observed in 3 separate clones of each dominant negative Rho family protein. These results suggest an important role for Rac in MTLn3 cell protrusive activity and spreading on collagen.

Effects of Rho GTPases on the Tumorigenicity, Blood Burden and Lung Metastasis of MTLn3 Cells

These experiments showed that the three Rho family proteins performed distinguishable roles in regulating growth, morphology and motility in MTLn3 cells. The MTLn3 cells form tumors in nude mice $(50,51)$, however the molecular mechanisms and the role of the Rho family proteins in MTLn3 growth in vivo were unknown. Implantation experiments were therefore conducted in nude mice as described in Materials and Methods on 3 separate occasions. The growth of MTLn3 tumors in vivo at 5 weeks was reduced by more than $95 \%$ by N17Racl or N17Cdc42 and by 30 - to $40 \%$ with the N19RhoA expressing cells (Table 1). These studies suggest that Rac and Cdc42 may be more important for sustained in vivo growth of MTLn3 cells than Rho.

MTLn3 cells can metastasize to the lung after intravenous injection or implantation $(35,50,51)$. When subcutaneous implantation methods were used, tumor cell density in the blood correlated with lung metastasis, suggesting that efficient intravasation into the blood stream perhaps affects the genesis of the metastatic phenotype (35). To examine the role of Rho family proteins in MTLn3 cell metastasis, blood burden assays were performed after implantation of the stable MTLn3 Rho family dominant inhibitory lines into nude mice as recently described (35). Blood burdens were assessed either 5 weeks after implantation (Table 1), or after tumors were allowed to grow to the same size, at which point blood burden assays was determined (Fig. 7B). The number of circulating cells observed with each of the dominant negative Rho protein lines was reduced in number compared with wild type (Table 1). Western blotting of the colonies evidenced the presence of sustained expression of the epitope tags within the peripheral blood colonies (data not shown). To begin to distinguish effects of the Rho proteins on tumor growth, from effects on intravasation, tumors were grown to the same size and blood burden reassessed (Fig. 7B). When the Rho dominant inhibitory lines were grown for 


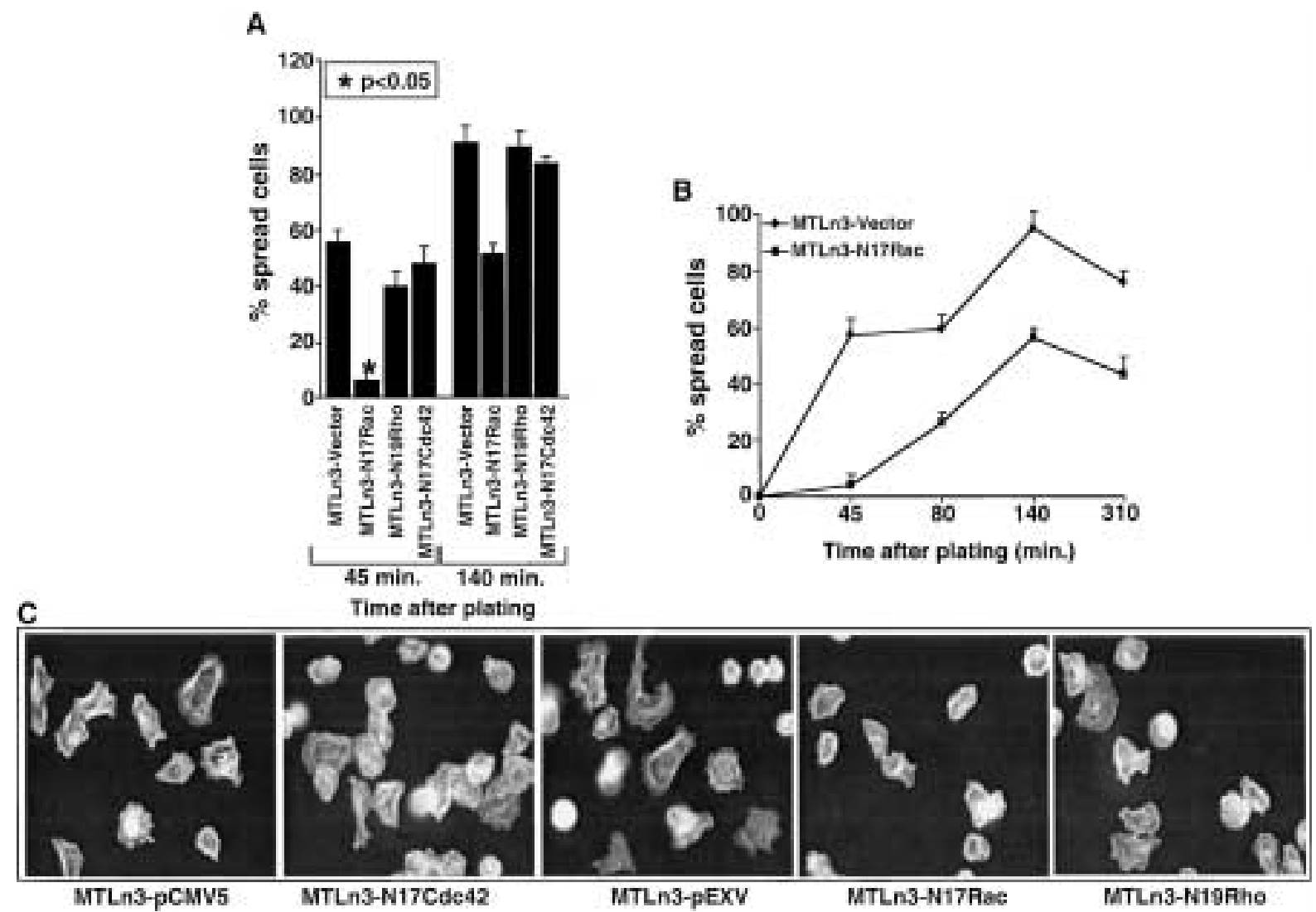

Fig. 6. Cell spreading. Parental and dominant inhibitory Rho protein-expressing MTLn3 cells were seeded onto 22 mm square collagen-coated glass cover slips and incubated in tissue culture plates. Cells were then fixed, permeabilized and stained with FITC-phalloidin at various time points. Spread cells were counted at $45 \mathrm{~min}$ and $140 \mathrm{~min}$ for all preparations (A) and also at 80 min, $140 \mathrm{~min}$ and $310 \mathrm{~min}$ for N17Racl-expressing lines and their vector controls (B). The data are shown as the means \pm SEM for percentage positive cells in the 5 fields. Representative fields at 80 minutes $(C)$.

8.5 weeks to the same size as vector control lines at 5 weeks, blood burden was detectable but reduced compared to vector control for each of the Rho proteins (Fig. 7B). These findings suggest that each of the Rho proteins contribute to intravasation.
A quantitation of lung metastasis was next performed in animals implanted with the MTLn3 vector control and Rho dominant negative cell lines. At 5 weeks post implantation, all MTLn3 control cells (pEXV, pCDNA3) had formed widespread lung

Table 1. Tumorigenicity and blood burden in nude mice. The inhibitory Rho family MTLn3 lines were assessed for growth 5 weeks after implantation into nude mice. The mean tumor size \pm SEM of at least 3 separate experiments is shown. Colony forming assays were performed on the peripheral blood of nude mice 5 weeks after implantation with MTLn3 lines encoding the dominant inhibitory Rho proteins or control lines.

5 Weeks Growth

\begin{tabular}{ccc}
\hline $\begin{array}{c}\text { Tumor Size Diameter }(\mathrm{cm}) \\
(\text { Mean } \pm \text { SEM) }\end{array}$ & $\begin{array}{c}\text { Cells in Blood } \\
\text { (range) }\end{array}$ & $\begin{array}{c}\text { Lung Metastasis } \\
\text { (Mean } \pm \text { SEM) }\end{array}$
\end{tabular}

MTLn3-pCMV5

MTLn3-N17Cdc42

MTLn3-pEXV

MTLn3-N17Rac

MTLn3-N19Rho
$1.36 \pm 0.13$
0
$1.57 \pm 0.23$
0
$0.49 \pm 0.06$

$78-80$
0
$92-100$
0
$16-25$

$26 \pm 4.74$

0

$21 \pm 1.56$

0

0 


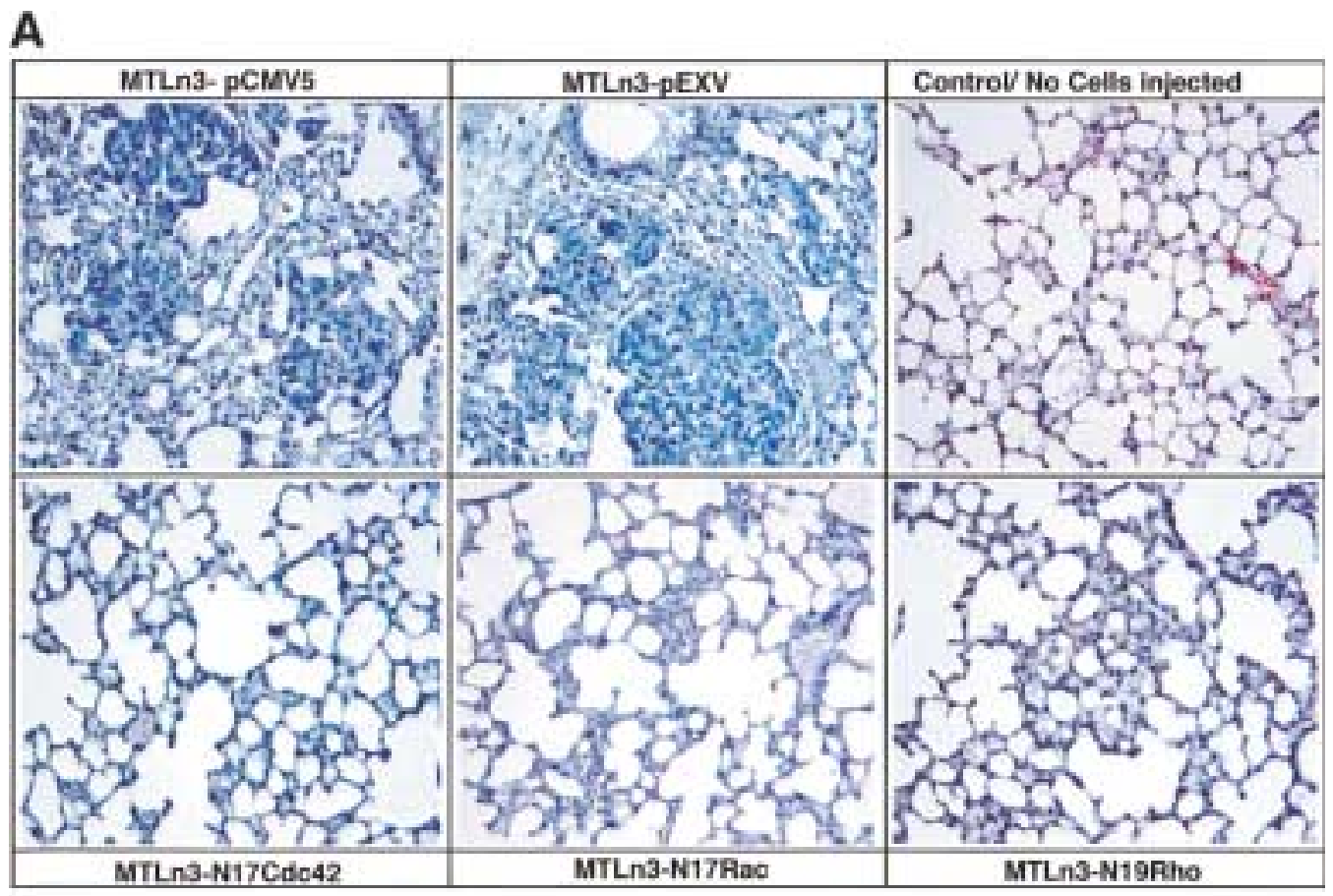

\begin{tabular}{|r|c|c|c|}
\cline { 2 - 4 } \multicolumn{1}{|c|}{$B$} & $\begin{array}{c}\text { Tumor size } \\
\text { diameter }(\mathrm{cm}) \\
\text { (Mean }+ \text { SEM) }\end{array}$ & $\begin{array}{c}\text { Cells in Blood } \\
\text { (range) }\end{array}$ & $\begin{array}{c}\text { Lung Motastasis } \\
\text { (Mean } \pm \text { SEM) }\end{array}$ \\
\hline MTLn3-pCMV5 & $1.36+0.13$ & $78-80$ & $26 \pm 4.74$ \\
\hline MTLn3-N17Cdo42 & $1.35+0.15$ & 4 & 0 \\
\hline MTLn3-pEXV & $1.57+0.23$ & $92-100$ & $21+1.56$ \\
\hline MTLn3-N17Aac & $1.35+0.18$ & 2 & 0 \\
\hline MTLn3-N19Rho & $1.80+0.21$ & 10 & 0 \\
\hline
\end{tabular}

Fig. 7. Blood burden and lung metastasis in nude mice. MTLn3 Rho inhibitory tumors were grown to the same size in the tissues of mice and CFU and lung metastasis assessed. (A) Representative examples of the lung tumors stained with H\&E are shown. (B) MTLn3 Rho inhibitory tumors were grown to the same size in the tissues of mice and blood burden (CFU) and lung metastasis were assessed, as described in Materials and Methods. Results are from at least 3 separate experiments under each condition.

metastatic foci (Fig. 7A). In contrast, none of the cell lines expressing dominant inhibitory Rho GTPases formed detectable macro foci, even though the N19RhoA lines were able to produce detectable tumor burdens in the peripheral blood.

\section{Discussion}

The current studies determined the role of specific Rho GTPase family members in mammary epithelial cell growth, guided migration and tumor metastasis (Table 2). and thereby identified the collaborative interactions between these family members for the full metastatic phenotype in vivo. The role of the Rho family proteins and their hierarchy of interaction in breast epithelial tumor cell function are not well understood. In addition, a systematic analysis of each of the diverse roles of Rho proteins had not been performed previously, especially in relation to understanding the fundamental biology of mammary tumor metastasis in vivo. Rac was the dominant regulator of cell spreading and both Rac and Cdc42 were important in MTLn3 cellular growth. The Rho family proteins regulate diverse signaling pathways controling a large number of essential functions, including the organization of the actin cytoskeletal, cell migration, gene transcription and cellular growth. In the current studies inhibition of either Rac, Rho or Cdc42 signaling blocked intravasation and lung metastasis suggesting that each of these 
Table 2. Summary of the role of Rho GTPases derived from analyses of the dominant inhibitory MTLn3 lines. The ability to regulate function completely ( $>90 \%$, triple arrow), partially $(40-70 \%$, double arrow), modestly (10-30\% single arrow) or not detected (none).

\begin{tabular}{|c|c|c|c|}
\hline & cdc42N17 & RacN17 & RhoN19 \\
\hline $\begin{array}{l}\text { Focal contacts and } \\
\text { tyrosine phosphorylation }\end{array}$ & Disruption & 4 & Disruption \\
\hline Protrusion/Spreading & $\downarrow$ & Ht & $\downarrow$ \\
\hline EGF-guided chemotaxis & $\downarrow 50 \%$ & $\$ 50 \%$ & $\$ 80 \%$ \\
\hline Cellular proliferation & $\downarrow 60 \%$ & $\nmid 60 \%$ & $\downarrow 20 \%$ \\
\hline Primary tumor growth & th & tr & $\downarrow 60 \%$ \\
\hline $\begin{array}{l}\text { Colony formation (CFU) } \\
\text { (cells in blood) }\end{array}$ & tht & th & tr \\
\hline Lung macro-metastasis & none & none & none \\
\hline Foci formation (Soft agar) & $\downarrow 70 \%$ & $\downarrow 75 \%$ & $\downarrow 10 \%$ \\
\hline
\end{tabular}

GTPases independently contribute to the final metastatic phenotype in vivo.

Several Rho family members have been shown to be essential for Ras transformation (1). Previous studies have identified specific roles for Rho family proteins in cultured cells, although cell type-specific differences have been observed. Different models have been proposed for the relationship between Cdc42, Rac and Rho. Hierarchical interactions have been identified between Rho family members, providing evidence for a "cascade" model (52), regulating the cytoskeleton in Swiss 3T3 fibroblasts, with Cdc42 activating Rac, which in turn activates Rho (7). In contrast with this model, an "antagonistic model" has been proposed in which Cdc42/Rac and Rho function in an antagonistic manner. For example Rac can downregulate Rho activity (53) and inactivation of Rho in neuroblastoma cells leads to neurite extension which is inhibited by either Cdc42-N17 or RaclN17 (54). A "convergent" pathway model was proposed to define interactions between Rho proteins in several other cell types (49), for example, during integrin-mediated signaling $(49,55,56)$. In fibroblasts, several studies suggested that Ras, Rac, and Rho function in a cascade relationship of interdependency (7), while other studies suggested "convergent" $(49,57)$ or perhaps "independent" pathways to explain the relationships between these proteins in other cell types. Finally, the Rho GTPases have important transcriptional functions in which Rac, Rho and Cdc42 act largely independently of each other (1). Although the current studies suggest that Rac, Rho and Cdc42 each contribute independently to the metastatic phenotype in vivo, further studies are required to distinguish whether the Rho GTPases function in a "cascade" or parallel pathway in mammary epithelial cells.

The role of Rho family members in defining mammary tumor cell morphology was assessed by immunofluorescence of the MTLn3 cytostructural proteins in the stable dominant negative lines. Rho and Cdc42 contributed to the co-localization of pTyr and vinculin without altering the total abundance of vinculin in the cell. pTyr was observed in a more dispersed pattern in cells expressing dominant negative RhoA (Fig. 2D vs. 2A). The loss of pTyr and vinculin co-staining in the N19RhoA MTLn3 cells is consistent with observations that quiescent cells with low Rho activity adhere and spread on ECM, but do not form well developed focal adhesions $(58,59)$. Focal contacts are one form of cell adhesion in cultured cells and contain anchor and cytoskeletal molecules including vinculin, paxillin and talin $(36,38)$, together with signal transduction molecules such as focal adhesion kinase (FAK) (39).

The assembly and tyrosine phosphorylation of FCs depends upon actomyosin contractility and is regulated by cytoplasmic factors, including Rho, or microtubular integrity $(37,40,42-45,60)$. FCs exhibit characteristically high levels of tyrosine phosphorylation (36). Vinculin, a major structural component of FCs, co-localizes at cell-matrix adhesions with pTyr in both primary human fibroblasts (61) and in the MTLn3 cells. Rho-induced FC formation requires a functional cellular contractile apparatus. Inhibiting intracellular contractile forces promotes disassembly and prevents FC formation even though cells remain adherent to the substratum $(44,62)$. Rho is required for complete phosphorylation of FAK induced by matrix adhesion (49), although FAK is phosphorylated at multiple sites and some Rho-independent FAK phosphorylation also occurs upon integrin aggregation (63). The observation that inhibition of Rac signaling did not interfere with pTyr and vinculin co-localization is consistent with findings that FAK phosphorylation and paxillin tyrosine phosphorylation are Rho-dependent and Rac-independent in Ratl cell fibroblasts (49). 
The reduction in vinculin staining at FCs in the N17Cdc42 lines suggests that Cdc42 activity contributes to FC formation in MTLn3 cells as previously described in fibroblasts.

The current studies demonstrated a critical role for Racl in MTLn3 cell spreading and protrusion. These findings of diminished cell spreading in MTLn3 cells expressing dominant negative Racl are consistent with studies of spreading on fibronectin which was shown to be selectively Rac-dependent in T lymphocytes (64) and in fibroblasts (49). The directional migration of Ratl cells towards PDGF-BB, LPA or fibronectin was blocked by N17Racl and not by dominant negative mutants of RhoA or Cdc42 $(11,13)$. Inhibition of spreading by the dominant inhibitory Racl was associated with a modest increase in the number of FCs which were PTyr containing. These findings are consistent with observations in NR6 fibroblasts in which FC disassembly was associated with EGF-enhanced migration into an acellular area (46). Racl is activated by a variety of tyrosine kinase receptors including plateletderived growth factor (PDGF), EGF and insulin (65). The adhesion and spreading of $\mathrm{T}$ cells provides a more streamlined shape reducing shear imposed upon them by vascular flow and may have analogous functions for mammary epithelial cells. The current studies in MTLn3 mammary adenocarcinoma cells, together with previous studies in Swiss 3T3 and endothelial cells, suggest that the role of Racl in cell spreading is well conserved between cell types.

Guided-cell migration in response to a chemotactic gradient involves processes that are distinct from random protrusions and motility $(66,67)$. During guided chemotaxis, focal adhesion disassembly occurs both at the trailing and the leading edge. MTLn3 cells demonstrate classical ameboid chemotaxis on a planar surface in response to EGF (24). Herein, dominant inhibitory Racl and Cdc42 reduced EGF-induced guided chemotaxis $50 \%$, and N19RhoA by $90 \%$. Rho function is necessary to establish classical focal adhesion allowing stress fibers to anchor to the exctracellular surface (59). Smaller adhesion complexes at the periphery of the cell are induced by activation of Rac and Cdc42 (7). As the relative abundance of the N19RhoA and N17Racl in the stable lines was similar by western blotting, and Rac preferentially regulated MTLn3 cellular spreading, these findings suggest that individual GTPases play distinct roles in spreading compared with guided chemotaxis.

Analysis of Rho family proteins in anchorageindependent growth demonstrated that Cdc42 and Rac function contributes to mammary adenocarcinoma cellular proliferation and growth in soft agar. Although Rho played a dominant role in guided chemotaxis, the contribution of Rho to cellular proliferation and contact-independent growth of the MTLn3 cells assessed in soft agar assays was relatively modest. This is similar to the situation in fibroblasts
$(47,48,68-71)$. The induction of anchorage independence by oncogenic Ras however requires Rho, Rac and Cdc42 $(47,48,71)$ and inhibition of Rho as well as Rac and Cdc42 can inhibit $G_{1}$ phase progression in other cell types (72). The PAK kinases may serve as Rac and Cdc42 effectors involved in integrin-mediated ERK activation and integrinmediated adhesion is required for efficient coupling of Racl to PAKl (73). Overexpression of activated Rac and Cdc42 can bypass this need and induce anchorage-independent ERK activity $(69,74)$ and expression of the cyclin A gene, a key regulator of $S$ phase progression (68-70). The enhancement of Gl phase progression and cellular growth by Rac appears to be strongly related to the induction of the cyclin Dl gene. Activating mutations of Rac promote DNA synthesis and activate the cyclin DI promoter directly $(28,75)$ and inhibition of Rac or Cdc42 block cyclin Dl expression and contact independent growth induced by oncogenic Neu (25). The modest effect of blocking Rho on MTLn3 growth in soft agar, compared with RaclN17 and Cdc42, may reflect the relatively greater importance of Rac/Cdc42 in contact-independent growth of mammary adenocarcinoma cells.

The process of metastasis to the lungs involves several independent processes including migration, invasion of tissues, intravasation and growth. Inhibition of Rac, or Cdc42 blocked growth of MTLn3 cells in nude mice significantly better than N19RhoA at 5 weeks. When tumors were grown to a similar size, each of the dominant inhibitory Rho family members significantly reduced the number of colonies detectable in the peripheral blood by more than $90 \%$. Invasion of tissues may involve induction of proteases through Rho family protein-dependent mechanisms including induction of cytokines such as IL- $1 \alpha$ which thereby activates collagenase- 1 gene expression (76).

It is clear from a number of studies that Rho family proteins play important but distinguishable roles in cell growth and invasion of cellular matrix (1). Although Rho proteins had been postulated to regulate cellular metastasis, the requirement for Rho proteins in regulating breast cancer metastasis in vivo using a heterologous system had not previously been determined. Dominant negative mutants of Rho family proteins block serum-induced DNA synthesis in Swiss 3T3 cells (72). Ratl transformation induced by activating mutants of ErbB-2 is also blocked by dominant inhibitory Rho proteins (25). Despite the importance of the EGF receptor and its related family members to mammary epithelial cell growth, the role of Rho proteins in EGF receptor-dependent growth is poorly understood, particularly in the mammary epithelium. MTLn3 cells proliferate in response to EGF or serum (77), and inhibition of either Cdc42 or Rac, but not Rho activity, significantly reduced cellular proliferation (Fig. 5) and growth in soft agar (Fig. 6). An activating mutant of Racl, but not Cdc42, enhanced cell growth in the absence of serum in Ratl cells (48) 
further suggesting that each RhoA protein family member regulates growth in a distinct manner. Our studies using MTLn3 cells suggest an important role for Rac and Cdc42 in MTLn3 cellular proliferation and growth in soft agar.

Taken together, the in vitro studies in MTLn 3 cells showed that Rho family GTPases are differentially employed in signaling cell morphology changes, motile functions and aspects of growth that correlate with tumorigenesis and metastasis. Primary mammary tumor size was reduced at 5 weeks by each of the dominant inhibitory Rho family proteins. When tumors were grown to the same size, the reduced intravasation assessed by blood burden, suggested that entry into, and survival in, the peripheral blood is regulated by each of the Rho GTPases examined and is not simply a function of reduced tumor mass. These findings are consistent with recent studies in which RhoC was shown to play an important role in the metastastatic behaviour of melanoma cells (78). The events governing entry into the peripheral blood and survival may include resistance to shear forces, deformability, apoptosis in the absence of substratum and intravasation at the primary site (35). While the role of the Rho family proteins in these events remains to be determined, the N17Racl MTLn3 cells were found to have enhanced sensitivity to osmolar stress (RGP, BB, unpublished). In conclusion these experiments establish, for the first time, a critical role for Rho proteins in the regulation of mammary tumor growth and blood burden.

\section{Acknowledgments}

This work was supported in part by RO1CA70897 and ROICA75503 (to RGP) and awards from the Susan G. Komen Breast Cancer Foundation and Breast Cancer Alliance Inc. RGP is a Monique Weill-Caulier and Irma T. Hirschl Scholar. Work conducted at the Albert Einstein College of Medicine was supported by Cancer Center Core National Institutes of Health grant 5-P30-CA13330-26. MPL is supported by NIH R01-CA-80250. The authors acknowledge the Analytical Imaging Facility and Michael Cammer for skillful help on microscopy and image analysis. We thank Dr. Perry Bickel, Washington University, St Louis, MO, for a generous gift of guanine nucleotide dissociation inhibitor (GDI) antibody.

\section{References}

1. Van Aelst L, D'Souza-Schorey C. (1997) Rho GTPases and signaling networks. Genes Dev. 11: 2295-2322.

2. Ridley AJ, Paterson HF, Johnston CL, et al. (1992) The small GTP-binding protein rac regulates growth factor-induced membrane ruffling. Cell 70: 401-410.

3. Ridley AJ. (1994) Membrane ruffling and signal transduction. Bioessays 16: 321-327.

4. Evers EE, Zondag GCM, Malliri A, et al. (2000) Rho family of proteins in cell adhesion and cell migration. Eur. J. of Cancer 36: $1269-1274$.
5. Ridley AJ, Hall A. (1992) The small GTP-binding protein rho regulates the assembly of focal adhesions and actin stress fibers in response to growth factors. Cell 70: 389-399.

6. Kozma R, Ahmed S, Best A, Lim L. (1995) The Ras-related protein Cdc42Hs and bradykinin promote formation of peripheral actin microspikes and filopodia in Swiss $3 \mathrm{~T} 3$ fibroblasts. Mol. Cell. Biol. 15: 1942-1952.

7. Nobes CD, Hall A. (1995) Rho, Rac, and Cdc42 GTPases regulate the assembly of multimolecular focal complexes associated with actin stress fibers, lamellipodia, and filopodia. Cell 81: 53-62.

8. Takaishi K, Kikuchi A, Kuroda S, et al. (1993) Involvement of rho p2 1 and its inhibitory GDP/GTP exchange protein (rho GDI) in cell motility. Mol. Cell. Biol. 13(1): 72-79.

9. Stasia M-J, Jouan A, Bourmeyster N, et al. (1991) ADPribosylation of a small size GTP-binding protein in bovine neutrophils by the C3 exoenzyme of Clostridium botulinum and effect on the cell motility. Biochem. Biophys. Res. Comm. 180: 615-622.

10. Allen WE, Zicha D, Ridley AJ, Jones GE. (1998) A role for cdc42 in macrophage chemotaxis. J. Cell. Biol. 141: 11471157.

11. Anand-Apte B, Zetter BR, Viswanathan A, et al. (1997) Platelet-derived growth factor and fibronectin-stimulated migration are differentially regulated by the Rac and extracellular signal-regulated kinase pathways. J. Biol. Chem. 272: 30688-30692.

12. Keely PJ, Westwick JK, Whitehead IP, et al. (1997) Cdc42 and Racl induce integrin-mediated cell motility and invasiveness through PI(3)K. Nature 390: 632-636.

13. Banyard J, Anand-Apte B, Symons M, Zetter BR. (2000) Motility and invasion are differentially modulated by Rho family GTPases. Oncogene 19: 580-591.

14. Condeelis JS, Wyckoff JB, Bailly M, et al. (2001) Lamellipodia in Invasion. Seminars in Cancer Biology Apr 11: 119-128.

15. Liotta LA, Steeg PS, Stetler-Stevenson WG. (1991) Cancer metastasis and angiogenesis: an imbalance of positive and negative regulation. Cell 64: 327-336.

16. Neri A, Welch D, Kawaguchi T, Nicolson GL. (1982) Development and biologic properties of malignant cell sublines and clones of a spontaneously metastasizing rat mammary adenocarcinoma. J. Natl. Cancer Inst. 68: 507-517.

17. Welch DR, Neri A, Nicolson GL. (1983) Comparison of 'spontaneous' and 'experimental' metastasis using rat 13762 mammary adenocarcinoma metastatic cell clones. Invasion Metastasis 3(2): $65-80$.

18. Khazaie K, Schirrmacher V, Lichtner RB. (1993) EGF receptor in neoplasia and metastasis. Cancer Metastasis Rev. 12: 255-74.

19. Pedersen PH, Ness GO, Engebraaten O, et al. (1994) Heterogeneous response to the growth factors [EGF, PDGF (bb), TGF-alpha, bFGF, IL-2] on glioma spheroid growth, migration and invasion. Int. J. Cancer 56(2): 255-261.

20. Grotendorst GR, Soma Y, Takehara K, Charette M. (1989) EGF and TGF-alpha are potent chemoattractants for endothelial cells and EGF-like peptides are present at sites of tissue regeneration. J. Cell Physiol. 139(3): 617-623.

21. Blay J, Brown KD. (1985) Epidermal growth factor promotes the chemotactic migration of cultured rat intestinal epithelial cells. J. Cell Physiol. 124: 107-112.

22. Segall JE, Tyerich S, Boselli L, et al. (1996) EGF stimulates lamellipod extension in metastatic mammary adenocarcinoma cells by an actin-dependent mechanism. Clin. Exp. Metastasis 14: 61-72.

23. Chan A, Raft S, Bailly M, et al. (1998) EGF stimulates actin nucleation at the tip of the lamellipod in mammary adenocarcinoma cells. J. Cell. Science 111: 199-211.

24. Bailly M, Yan L, Whitesides GM, et al. (1998) Regulation of protrusion shape and adhesion to the substratum during chemotactic responses of mammalian carcinoma cells. Exp. Cell Res. 241: 285-299.

25. Lee RJ, Albanese C, Fu M, et al. (2000) Cyclin Dl is required for transformation by activated Neu and is induced through an E2F-dependent signaling pathway. Mol. Cell. Biol. 20: 672-683. 
26. Clarke N, Arenzana N, Hai T, et al. (1998) Epidermal growth factor induction of the c-jun promoter by a Rac pathway. Mol. Cell. Biol. 18(2): 1065-1073.

27. Westwick JK, Lee RJ, Lambert QT, et al. (1998) Transforming potential of Dbl family proteins correlates with transcription from the cyclin Dl promoter but not with activation of Jun $\mathrm{NH}_{2}$-terminal kinase, p38/Mpk2, serum response factor, or c-Jun. J. Biol. Chem. 273: 16739-16747.

28. Westwick JK, Lambert QT, Clark GJ, et al. (1997) Rac regulation of transformation, gene expression and actin organisation by multiple, PAK-independent pathways. Mol. Cell. Biol. 17: 1324-1335.

29. Zhang W, Razani B, Altschuler Y, et al. (2000) Caveolin-1 inhibits EGF-stimulated lamellipod extension and cell migration in metastatic mammary adenocarcinoma cells (MTLn3).Transformation suppressor effects of adenoviral-mediated gene delivery of caveolin-1. J. Biol. Chem. 275: 20717-20725.

30. Fu M, Wang C, Reutens AT, et al. (2000) p300 and P/CAF acetylate the androgen receptor at sites governing hormonedependent transactivation. J. Biol. Chem. 275: 20853-20860.

31. Bouzahzah B, Fu M, Iaavarone A, et al. (2000) Transforming growth factor $\beta 1$ recruits histone deacetylase 1 to a pl30 repressor complex in trangenic mice in vivo. Cancer Res. 60: $4531-4537$.

32. Albanese C, Johnson J, Watanabe G, et al. (1995) Transforming p2 $1^{r a s}$ mutants and c-Ets-2 activate the cyclin D1 promoter through distinguishable regions. J. Biol. Chem. 270: 23589-23597.

33. Watanabe G, Lee RJ, Albanese C, et al. (1996) Angiotensin II (AII) activation of cyclin D 1-dependent kinase activity. J. Biol. Chem. 271: 22570-22577.

34. Galbiati F, Volonte D, Engelman JA, et al. (1998) Targeted downregulation of caveolin-1 is sufficient to drive cell transformation and activate the p42/p44 MAP kinase cascade. ЕМВО J. 17: 6633-6648.

35. Wyckoff JB, Jones JG, Condeelis JC, Segall JE. (2000) A critical step in metastasis: in vivo analysis of intravasation at the primary tumor. Cancer Res. 60: 2504-2511.

36. Burridge K, Turner CE, Romer LH. (1992) Tyrosine phosphorylation of paxillin and pp 125FAK accompanies cell adhesion to extracellular matrix: a role in cytoskeletal assembly. J. Cell Biol. 119: 893-903.

37. Jockusch BM, Bubeck P, Giehl K, et al. (1995) The molecular architecture of focal adhesions. Annu. Rev. Cell Dev. Biol. 11: 379-416.

38. Yamada KM, Geiger B. (1997) Molecular interactions in cell adhesion complexes. Curr. Opin. Cell Biol. 9: 76-85.

39. Yamada KM, Miyamoto S. (1995) Integrin transmembrane signaling and cytoskeletal control. Curr. Opin. Cell Biol. 7: 681-689.

40. Zamir E, Katz B-Z, Aota S-I, et al. (1999) Molecular diversity of cell-matrix adhesions. J. Cell Sci. 1129: 1655-1669.

41. Helfman DM, Levy ET, Berthier C, et al. (1999) Caldesmon inhibits nonmuscle cell contractility and interferes with the formation of focal adhesions. Mol. Biol. Cell. 10: 3097-3112.

42. Pelham RJ, Wang YL. (1997) Cell locomotion and focal adhesions are regulated by substrate flexibility. Proc. Natl. Acad. Sci. USA 94: 13661-13665.

43. Craig SW, Johnson RP. (1996) Assembly of focal adhesions: progress, paradigms, and portents. Curr. Opin. Cell Biol. 8: 74-85.

44. Chrzanowska-Wodnicka M, Burridge K. (1996) Rho-stimulated contractility drives the formation of stress fibers and focal adhesions. J. Cell Biol. 133: 1403-1415.

45. Bershadsky A, Chausovsky A, Becker E, et al. (1996) Involvement of microtubules in the control of adhesion-dependent signal transduction. Curr. Biol. 6: 1279-1289.

46. Xie H, Pallero MA, Gupta K, et al. (1998) EGF receptor regulation of cell motility: EGF induces disassembly of focal adhesions independently of the motility-associated PLC (gamma) signaling pathway. J. Cell Science 111(5): 615-624.

47. Qiu R-G, Chen J, McCormick F, Symons M. (1995) A role for Rho in Ras transformation. Proc. Natl. Acad. Sci. USA 92: 11781-11785.
48. Qiu R-G, Abo A, McCormick F, Symons M. (1997) Cdc42 regulates anchorage-independent growth and is necessary for Ras transformation. Mol. Cell. Biol. 17: 3449-3458.

49. Clark EA, King WG, Brugge JS, et al. (1998) Integrinmediated Signals Regulated by Members of the Rho Family of GTPases. J. Cell Biol. 142: 573-586.

50. Lichtner RB, Kaufmann AM, Kittmann A, et al. (1995) Ligand mediated activation of ectopic EGF receptor promotes matrix protein adhesion and lung colonization of rat mammary adenocarcinoma cells. Oncogene 10: 1823-1832.

51. Kaufmann AM, Lichtner RB, Schirrmacher V, Khazaie K. (1996) Induction of apoptosis by EGF receptor in rat mammary adenocarcinoma cells coincides with enhanced spontaneous tumour metastasis. Oncogene 13: 2349-2358.

52. Chant J, Stowers L. (1995) GTPase cascades choreographing cellular behavior: movement, morphogenesis, and more. Cell 81(1): $1-4$.

53. Sander EE, ten Klooster JP, van Delft S, et al. (1999) Rac downregulates Rho activity: reciprocal balance between both GTPases determines cellular morphology and migratory behavior. J. Cell Biol. 147: 1009-1022.

54. Kozma R, Sarner S, Ahmed S, Lim L. (1997) Rho family GTPases and neuronal growth cone remodeling: relationship between increased complexity induced by Cdc42Hs, Racl and acetylcholine and collapse induced by RhoA and lysophosphatidic acid. Mol. Cell. Biol. 17(3): 1201-1211.

55. King WG, Mattaliano MD, Chan TO, et al. (1997) Phosphatidylinositol 3-kinase is required for integrin-stimulated AKT and Raf-1/mitogen-activated protein kinase pathway activation. Mol. Cell Biol. 17: 4406-4418.

56. Clark EA, Hynes RO. (1996) Ras activation is necessary for integrin-mediated activation of extracellular signal-regulated kinase 2 and cytosolic phospholipase A2 but not for cytoskeletal organization. J. Biol. Chem. 271: 14814-14818.

57. Rodriguez-Viciana P, Warne PH, Khwaja A, et al. (1997) Role of phosphoinositide 3-OH kinase in cell transformation and control of the actin cytoskeleton by ras. Cell 89: 457-467.

58. Ben-Ze'ev A, Geiger B. (1998) Differential molecular interactions of beta-catenin and plakoglobin in adhesion, signaling and cancer. Curr Opin Cell Biol. 10: 629-639.

59. Hotchin NA, Hall A. (1995) The assembly of integrin adhesion complexes requires both extracellular matrix and intracellular rho/rac GTPases. J. Cell. Biol. 131: 1857-1865.

60. Burridge K, Chrzanowska-Wodnicka M, Zhong CL. (1997) Focal adhesion assembly. Trends Cell Biol. 7: 342-347.

61. Katz BZ, Zamir E, Bershadsky A, et al. (2000) Physical State of the Extracellular Matrix Regulates the Structure and Molecular Composition of Cell-Matrix Adhesions. Mol. Bio. Cell 11(3): 1047-1060.

62. Volberg T, Geiger B, Citi S, Bershadsky AD. (1994) Effects of protein-kinase inhibitor $\mathrm{H}-7$ on the contractility, integrity, and membrane anchorage of the microfilament system. Cell Motil. Cytoskel. 29: 321-338.

63. Miyamoto S, Akiyama SK, Yamada KM. (1995) Synergistic roles for receptor occupancy and aggregation in integrin transmembrane function. Science 267: 883-885.

64. D'Souza-Schorey C, Boettner B, Van Aelst L. (1998) Rac Regulates Integrin-Mediated Spreading and Increased Adhesion of T Lymphocytes. Mol. Cell Biol. 18: 3936-3946.

65. Kjoller L, Hall A. (1999) Signaling to Rho GTPases. Exp. Cell Research 253: 166-179.

66. Aznavoorian S, Stracke ML, Parsons J, et al. (1996) Integrin alphav-beta3 mediates chemotactic and haptotactic motility in human melanoma cells through different signaling pathways. J. Biol. Chem. 271: 3247-3254.

67. Huttenlocher A, Ginsberg MH, Horwitz AF. (1996) Modulation of cell migration by integrin-mediated cytoskeletal linkages and ligand-binding affinity. J. Cell Biol. 134: 1551-1562.

68. Gjoerup O, Lukas J, Bartek J, Willumsen BM. (1998) Rac and Cdc42 are potent stimulators of E2F-dependent transcription capable of promoting retinoblastoma susceptibility gene product hyperphosphorylation. J. Biol. Chem. 273: 1881218818. 
69. Aplin AE, Juliano RL. (1999) Integrin and cytoskeletal regulation of growth factor signaling to the MAP kinase pathway. J. Cell Sci. 112(5): 695-706.

70. Philips A, Roux P, Coulon V, et al. (2000) Differential effect of rac and cdc42 on p38 kinase activity and cell cycle progression of nonadherent primary mouse fibroblasts. J. Biol Chem. 275(8): 5911-5917.

71. Qiu R-G, Chen J, Kirn D, et al. (1995) An essential role for Rac in Ras transformation. Nature 374: 457-459.

72. Olson MF, Ashworth A, Hall A. (1995) An essential role for Rho, Rac and Cdc42 GTPases in cell cycle progression through $\mathrm{G}_{1}$. Science 269: 1270-1272.

73. Coniglio SJ, Jou T-S, Symons M. (2001) Racl protects epithelial cells against anoikis. J. Biol. Chem. 276: 28113-28120.

74. del Pozo MA, Price LS, Alderson NB, et al. (2000) Adhesion to the extracellular matrix regulates the coupling of the small GTPase Rac to its effector PAK. EMBO J. 19: 20082014.

75. Joyce D, Bouzahzah B, Fu M, et al. (1999) Integration of Rac-dependent regulation of cyclin Dl transcription through an NF- $\kappa$ B-dependent pathway. J. Biol. Chem. 274: 25245-25249.

76. Kheradmand F, Werner E, Tremble P, et al. (1998) Role of Racl and oxygen radicals in collagenase- 1 expression induced by cell shape change. Science 280: 898-902.

77. Lichtner RB, Wiedemuth M, Kittmann A, et al. (1992) Ligand-induced activation of epidermal growth factor receptor in intact rat mammary adenocarcinoma cells without detectable receptor phosphorylation. J Biol Chem. 267: 11872-11880.

78. Clark EA, Golub TR, Lander ES, Hynes RO. (2000) Genomic analysis of metastasis reveals an essential role for RhoC. Nature 406: 532-535. 